\title{
Clustering of developmental delays in Bavarian preschool children - a repeated cross-sectional survey over a period of 12 years
}

Heribert L Stich ${ }^{1,2}$, Alexander Krämer ${ }^{2}$ and Rafael T Mikolajczyk ${ }^{3, *^{*}}$

\begin{abstract}
Background: While most children display a normal development, some children experience developmental delays compared to age specific development milestones assessed during school entry examination. Data exist on prevalence of delays in single areas, but there is lack of knowledge regarding the clustering patterns of developmental delays and their determinants.

Methods: During the observation period 1997-2008, 12399 preschool children (5-7 years of age) in one district of Bavaria, Germany, were assessed in twelve schooling-relevant development areas. The co-occurrence of developmental delays was studied by means of Pearson's correlation. Subsequently, a two-step cluster algorithm was applied to identify patterns of developmental delays, and multinomial logistic regression was conducted to identify variables associated with the specific patterns.

Results: Fourteen percent of preschool children displayed developmental delays in one and 19\% in two or more of the studied areas. Among those with at least two developmental delays, most common was the combination of delays in "fine motor skills" + "grapho-motor coordination" (in 9.1\% of all children), followed by "memory/concentration" + "endurance" (5.8\%) and "abstraction" + "visual perception" (2.1\%). In the cluster analysis, five distinct patterns of delays were identified, which displayed different associations with male gender and younger age.

Conclusions: While developmental delays can affect single areas, clustering of multiple developmental delays is common. Such clustering should be taken into account when developing diagnostic tests, in pediatric practice and considering interventions to reduce delays.
\end{abstract}

Keywords: Developmental delays, Distribution pattern, Preschool children, Preventive medicine

\section{Background}

In the international comparison, developmental delays are defined and assessed differently across countries [1-3]. This is not only the case for single developmental delays, but even more for the co-occurrence of delays. In Germany, the term "performance deficits" was defined with focus on relevant skills for entering $1^{\text {st }}$ class of primary school [3]. In this definition only the occurrence of single development delays was recognized [3]. In contrast, in the U.S.A. and in Canada primarily specific combinations of developmental disabilities were in the focus of interest. The term

\footnotetext{
* Correspondence: rafael.mikolajczyk@helmholtz-hzi.de

${ }^{3}$ Department of Epidemiology, Helmholtz Centre for Infection Research, Braunschweig, Germany

${ }^{4}$ Hannover Medical School, Hannover, Germany

Full list of author information is available at the end of the article
}

"development disability" was used for developmental delays which manifested before the $18^{\text {th }}$ birthday and affected daily functioning in three or more of the following areas: capacity for independent living, economic self-sufficiency, learning, mobility, language receptive and expressive, selfcare, and self-direction [4]. Thus, it is not surprising that in the Anglo-Saxon countries the incidence of combined developmental delays received more attention in the relevant literature than in German-speaking countries.

The acquisition of various skills in the context of individual development is a very differentiated process and varies from child to child $[5,6]$. Although the vast majority of children in the Western industrialized countries experience an intact somatic, psychological and social development, a variety of developmental trajectories can

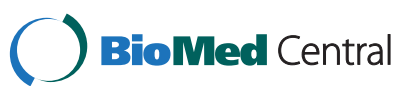

(c) 2014 Stich et al.; licensee BioMed Central Ltd. This is an open access article distributed under the terms of the Creative Commons Attribution License (http://creativecommons.org/licenses/by/2.0), which permits unrestricted use, distribution, and reproduction in any medium, provided the original work is properly cited. 
be observed and developmental delays can be identified $[1,7]$. Most of previous studies considered delays independently of each other, with focus on motor and language development on the one side [2], and cognitive or mental delays in specific patient populations on the other side $[8,9]$. In the diagnostic practice for a non-negligible number of preschool children not only a single, isolated developmental delay, but a clustering of delays can be observed. Publications in the area of combined developmental delays appeared first in the early 1990s. Bishop [10] and Nicholoson and Fawcett [11] noticed a combination of delays in development of coordination and language disorders in children. According to other authors, language disorders frequently were associated with attention disorders $[9,12,13]$ or with abnormalities in motor skills, attention and psychosocial development $[3,14,15]$. While the observations of co-occurrence of developmental delays were made, no exact frequencies were reported. This fact represents a considerable deficit, because it is known that especially combined developmental delays usually have moderate or strong expression, while isolated delays have rather a mild expression [16]. Further, combined developmental delays have a tendency to persistence [17]. The knowledge of these facts might be important for diagnostics in the field of childhood development.

The present study aimed to assess the co-occurrence of developmental delays using data from a school entry examination, which is mandatory for preschool children in Germany and therefore provides an unselected populationbased, non-clinical sample. Prevalences of single developmental delays were subject to previous analyses in the same District of Bavaria $[18,19]$.

\section{Methods}

\section{Study design}

The present investigation is based on a repeated survey using the framework of the mandatory school entry examination in Germany and therefore including each year the complete age cohort at about 5-6 years [20]. In the presence of a severe disease of the eyes or hearing, the child was not considered for standardized school entry examination and not included in the sample. We included in the analysis all children participating in school entry examinations in the years 1997-2008 who had primary residence in the Lower Bavarian District Dingolfing-Landau ( $\mathrm{N}=12$ 399).

\section{Content of the examination}

In the study district, a manual of the Working Group "School and Youth Health Care in the Public Health Service" was used in a slightly modified form [21]. The corresponding test battery was designed to assess four dimensions of development with corresponding subareas - in total 12 developmental areas (Table 1). All tests used in the diagnostics are standardized, and every child had to absolve the complete examination. If a test could not be performed as requested, this was considered as a developmental delay in the corresponding subarea.

Diagnosis and documentation of findings were performed by the investigation team of the School Health Service in the district of Dingolfing- Landau. During the entire twelve years study period, this medical team was composed of the same personnel and used the same approach. The analysis is based on anonymized data obtained in these routine examinations and was approved by the ethics committee of the University of Bremen.

\section{Statistical analyses}

For data analysis, software package SPSS 19.0 was used [22]. First, we performed descriptive analyses of the sample. Second, in order to assess if some delays are more often combined with others, we used Pearson's correlation coefficient. Given the large sample size, even marginal correlations were significant. Therefore, instead of using significance criterion, we used Cohen's classification of effect sizes for interpretation and focused only on correlations of 0.5 or higher which are considered strong [23]. Next, among children with at least one delay, we studied the clustering of delays beyond just a combination of two delays by means of a two-step cluster algorithm [24]. Finally, we used multinomial logistic regression analysis to identify variables independently associated with specific patterns of delays, considering children with "no delays" as the reference group.

\section{Results}

Sociodemographic characteristics

The District of Dingolfing-Landau has over 91,000 inhabitants. The area has a rural infrastructure besides one industrial factory of automobiles. About $93 \%$ of the population has the German nationality. Average age of the examined children was 5.95 years (standard deviation 0.39 ); $51.7 \%$ of all children were male, and $89.5 \%$ had the German nationality.

\section{Description of prevalence of delays}

Of all 12,399 preschool children examined during the study period, approximately two-thirds did not demonstrate any delays, $14.2 \%$ had one, $6.8 \%$ had two, and the remaining $11.6 \%$ - three or more developmental delays. Highest co-occurrences of delays were found for fine body coordination and grapho-motor coordination (9.1\%) and for memory/concentration and endurance (5.8\%) (Table 2).

\section{Clustering of developmental delays}

Correlations of developmental delays in different areas

Developmental delays of fine motor coordination and grapho-motor coordination showed the strongest correlation 
Table 1 Modification of "Bavarian School Entry Model" used in the current study for the assessment of developmental delays

\begin{tabular}{|c|c|c|c|}
\hline Assessment & $\begin{array}{l}\text { Main areas of } \\
\text { development }\end{array}$ & Subareas & Standardized investigation procedures \\
\hline \multirow[t]{11}{*}{ Biomedical } & \multirow[t]{3}{*}{ Motor } & Gross motor & $\begin{array}{l}\text { Standing on one leg (at least } 10 \text { s, both legs, max. } 3 \text { trials), } \\
\text { jumping on one leg (at least } 5 \text { times on each leg), walking } \\
\text { like a rope dancer ( } 20 \text { steps forwards and backwards), } \\
\text { walking and clasping hands (walk a } 10 \text { m walk a } 10 \text { m walk } \\
\text { clasping hands at each step) }\end{array}$ \\
\hline & & Fine body coordination & $\begin{array}{l}\text { Finger-opposition-test (touching with the thumb all other } \\
\text { fingers from } 2 \text { to five and backwards, max. } 3-4 \text { s pro sequence, } \\
\text { per hand), fist-palm-test (one hand clenched to fist the other } \\
\text { as palm and change of hands } 7-10 \text { times in } 10 \text { s), thumb-palm- } \\
\text { test (as previous one but with the thumb and palm) }\end{array}$ \\
\hline & & Grapho-motor coordination & $\begin{array}{l}\text { Painting of a human figure (head with eyes, mouth, ears, hairs, } \\
\text { body and hands and legs), tracing of geometric shapes (four shapes: } \\
\text { circle, cross, triangle, square), colouring of objects (colouring should } \\
\text { stay within shapes), drawing of curved lines (line should stay within } \\
\text { a curved } 15 \mathrm{~cm} \text { long } 1 \mathrm{~cm} \text { wide area), connecting points with a } \\
\text { straight line (two points in } 15 \mathrm{~cm} \text { distance should be connected } \\
\text { by a straight line) }\end{array}$ \\
\hline & \multirow[t]{3}{*}{ Language } & Pronunciation & $\begin{array}{l}\text { Repeating words (8-10 words with specific consonants and vocals } \\
\text { have to be repeated), repeating simple sentences ( } 7 \text { defined sentence } \\
\text { with increasing difficulties); repeating nonsense-words ( } 7 \text { defined } \\
\text { non-sense words with specific consonants and vocals) (one } \\
\text { misspelling is acceptable) }\end{array}$ \\
\hline & & Grammar & $\begin{array}{l}\text { Retelling a short story ( } 5 \text { sentences), explaining rules of a known } \\
\text { game (for example football) }\end{array}$ \\
\hline & & Rhythm of speech & Repeating of longer sentences with specific sounds \\
\hline & \multirow[t]{5}{*}{ Cognition } & Memory \& concentration & $\begin{array}{l}\text { Repeating sentences with } 7-10 \text { words including } 3 \text { adjectives; repeating } \\
4 \text { single numbers in a correct sequence }\end{array}$ \\
\hline & & Endurance & Capacity to attend during the examination (15-20 minutes) \\
\hline & & Abstraction & $\begin{array}{l}\text { Building pairs ( } 14 \text { pictures with household goods), finding a common } \\
\text { subject of various objects, finding difference between pictures }\end{array}$ \\
\hline & & Visual perception & $\begin{array}{l}\text { Recognition of simple geometric figures or silhouettes of figures } \\
\text { and animals }\end{array}$ \\
\hline & & Arithmetics & Counting from 1 to 10 in correct sequence \\
\hline \multirow[t]{3}{*}{ Psychological } & \multirow[t]{3}{*}{ Psychosocial } & & $\begin{array}{l}\text { Erratic behaviour, overly bonded mother (no separation possible } \\
\text { during examination), hostility towards examiner }\end{array}$ \\
\hline & & & Major emotional mood \\
\hline & & & Psycho-motor agitation, inability to sit calmly during examination \\
\hline
\end{tabular}

Note: There is some overlap between tests for fine motor and grapho-motor development, requiring interpretation by the attending expert.

(Pearson's correlation coefficient $r=0.78$, Table 2). Also, a high correlation was found between developmental delays in the subareas of memory/concentration and endurance $(\mathrm{r}=0.66)$, and in the subareas of capacity for abstract thinking and visual perception $(\mathrm{r}=0.54$, Table 2$)$. The remaining correlation coefficients were below 0.5. Despite the differences in strength, all correlations were highly significant $(\mathrm{p}<0.0001)$.

\section{Patterns of concurrent delays}

In the cluster analysis restricted to children with a least one developmental delay, five distinct patterns of developmental delays were identified (Table 3). We described the patterns based on most frequent areas of impairment in the corresponding pattern using the following algorithm: first, all those which were recorded in at least $50 \%$ of cases; second, if there was only one area above $50 \%$, a second area with high ratings was included; and third, if multiple delays to be included in the definition differed by less than $5 \%$, they were all included in the description of the given pattern. The first pattern were isolated disorders in pronunciation of speech, the second pattern combined delays in subareas of pronunciation, grammar, rhythm of speech and psychosocial development, the third pattern - deficits of subareas of memory/concentration, endurance, abstraction and visual perception. The fourth pattern was dominated by delays of fine body coordination and grapho-motor coordination. The fifth pattern was a combination of cognitive and motor developmental delays (fine motor coordination, grapho-motor coordination, 
Table 2 Prevalence of combinations of developmental delays $(c p=$ in percent) and corresponding correlations $(r=$ Pearson's correlations coefficients)

\begin{tabular}{|c|c|c|c|c|c|c|c|c|c|c|c|c|}
\hline & $\begin{array}{l}\text { Gross } \\
\text { motor }\end{array}$ & $\begin{array}{l}\text { Fine body } \\
\text { coordination }\end{array}$ & $\begin{array}{l}\text { Grapho-motor } \\
\text { coordination }\end{array}$ & Pronunciation & Grammar & $\begin{array}{l}\text { Rhythm } \\
\text { of speech }\end{array}$ & $\begin{array}{l}\text { Memory \& } \\
\text { concentration }\end{array}$ & Endurance & Abstraction & $\begin{array}{l}\text { Visual } \\
\text { perception }\end{array}$ & Arithmetic & Psychosocial \\
\hline Gross motor & & $r=0.38$ & $r=0.30$ & $r=0.11$ & $r=0.13$ & $r=0.09$ & $r=0.30$ & $r=0.27$ & $r=0.19$ & $r=0.21$ & $r=0.20$ & $r=0.23$ \\
\hline Fine body coordination & $\mathrm{cp}=3.5 \%$ & & $r=0.78$ & $r=0.13$ & $r=0.16$ & $r=0.09$ & $r=0.36$ & $r=0.32$ & $r=0.19$ & $r=0.20$ & $r=0.25$ & $r=0.23$ \\
\hline $\begin{array}{l}\text { Grapho-motor } \\
\text { coordination }\end{array}$ & $c p=2.6 \%$ & $\mathrm{cp}=9.1 \%$ & & $r=0.12$ & $r=0.17$ & $r=0.09$ & $r=0.33$ & $r=0.33$ & $r=0.20$ & $r=0.20$ & $r=0.25$ & $r=0.22$ \\
\hline Pronunciation & $c p=1.8 \%$ & $c p=3.0 \%$ & $c p=2.4 \%$ & & $r=0.23$ & $r=0.10$ & $r=0.12$ & $r=0.11$ & $r=0.07$ & $r=0.08$ & $r=0.08$ & $r=0.09$ \\
\hline Grammar & $c p=0.8 \%$ & $c p=1.4 \%$ & $c p=1.2 \%$ & $\mathrm{cp}=2.0 \%$ & & $r=0.19$ & $r=0.22$ & $r=0.19$ & $r=0.13$ & $r=0.13$ & $r=0.12$ & $r=0.13$ \\
\hline Rhythm of speech & $c p=0.6 \%$ & $\mathrm{cp}=0.8 \%$ & $\mathrm{cp}=0.7 \%$ & $c p=1.0 \%$ & $c p=0.8 \%$ & & $r=0.10$ & $r=0.06$ & $r=0.05$ & $r=0.07$ & $r=0.06$ & $r=0.06$ \\
\hline $\begin{array}{l}\text { Memory and } \\
\text { concentration }\end{array}$ & $c p=2.9 \%$ & $\mathrm{cp}=4.9 \%$ & $c p=3.9 \%$ & $c p=2.8 \%$ & $c p=1.7 \%$ & $c p=0.9 \%$ & & $r=0.66$ & $r=0.26$ & $r=0.29$ & $r=0.35$ & $r=0.35$ \\
\hline Endurance & $\mathrm{cp}=2.0 \%$ & $\mathrm{cp}=3.3 \%$ & $\mathrm{cp}=2.9$ & $\mathrm{cp}=1.9 \%$ & $\mathrm{cp}=1.2 \%$ & $c p=0.5 \%$ & $\mathrm{cp}=5.8 \%$ & & $r=0.27$ & $r=0.26$ & $r=0.32$ & $r=0.38$ \\
\hline Abstraction & $c p=1.0 \%$ & $c p=1.4 \%$ & $c p=1.3 \%$ & $c p=0.9 \%$ & $c p=0.6 \%$ & $c p=0.3 \%$ & $c p=1.8 \%$ & $c p=1.4 \%$ & & $r=0.54$ & $r=0.27$ & $r=0.23$ \\
\hline Visual perception & $\mathrm{cp}=1.3 \%$ & $\mathrm{cp}=1.8 \%$ & $\mathrm{cp}=1.5 \%$ & $c p=1.2 \%$ & $c p=0.6 \%$ & $c p=0.4 \%$ & $c p=2.3 \%$ & $c p=1.6 \%$ & $\mathrm{cp}=2.1 \%$ & & $r=0.27$ & $r=0.19$ \\
\hline Arithmetic & $\mathrm{cp}=1.2 \%$ & $\mathrm{cp}=2.0 \%$ & $\mathrm{cp}=1.7 \%$ & $c p=1.1 \%$ & $c p=0.6 \%$ & $c p=0.3 \%$ & $\mathrm{cp}=2.5 \%$ & $\mathrm{cp}=1.8 \%$ & $\mathrm{cp}=1.1 \%$ & $\mathrm{cp}=1.2 \%$ & & $r=0.20$ \\
\hline Psychosocial & $\mathrm{cp}=1.7 \%$ & $\mathrm{cp}=2.6 \%$ & $\mathrm{cp}=2.1 \%$ & $\mathrm{cp}=1.6 \%$ & $c p=0.8 \%$ & $c p=0.5 \%$ & $c p=3.4 \%$ & $\mathrm{cp}=1.4 \%$ & $\mathrm{cp}=1.2 \%$ & $\mathrm{cp}=1.2 \%$ & $\mathrm{cp}=1.2 \%$ & \\
\hline
\end{tabular}

Note: Correlations above 0.5 are marked in bold. All correlations were highly significant $(p<0.0001)$. 
Table 3 Patterns of developmental delays among preschool children with at least one delay in individual development*

\begin{tabular}{|c|c|c|c|c|c|}
\hline \multirow{2}{*}{$\begin{array}{l}\text { Subareas of } \\
\text { development }\end{array}$} & \multirow{2}{*}{$\begin{array}{l}\text { Pattern } 1 \\
\text { Isolated } \\
\text { disorders of } \\
\text { pronunciation }\end{array}$} & \multirow{2}{*}{$\begin{array}{l}\text { Pattern } 2 \\
\text { Combined delays of } \\
\text { pronunciation, grammar, } \\
\text { rhythm of speech and } \\
\text { psychosocial development }\end{array}$} & \multirow{2}{*}{$\begin{array}{l}\text { Pattern } 3 \\
\text { Delays in development } \\
\text { of memory, concentration, } \\
\text { endurance, abstraction } \\
\text { and visual perception }\end{array}$} & \multirow{2}{*}{$\begin{array}{l}\text { Pattern } 4 \\
\text { Delays of fine body } \\
\text { coordination and } \\
\text { grapho-motor } \\
\text { coordination }\end{array}$} & \multirow{2}{*}{$\begin{array}{l}\text { Pattern } 5 \\
\text { Combination of } \\
\text { delays in cognitive } \\
\text { and motor } \\
\text { development }\end{array}$} \\
\hline & & & & & \\
\hline Gross motor & $0 \%$ & $23 \%$ & 0.12 & $21 \%$ & $41 \%$ \\
\hline Fine body coordination & $0 \%$ & $0 \%$ & $0 \%$ & $93 \%$ & $94 \%$ \\
\hline Grapho-motor coordination & $0 \%$ & $0 \%$ & $0 \%$ & $68 \%$ & $77 \%$ \\
\hline Pronunciation & $100 \%$ & $30 \%$ & $21 \%$ & 22 & $30 \%$ \\
\hline Grammar & $0 \%$ & $29 \%$ & $8 \%$ & $4 \%$ & $21 \%$ \\
\hline Rhythm of speech & $0 \%$ & $34 \%$ & $3 \%$ & $5 \%$ & $10 \%$ \\
\hline Memory and concentration & $0 \%$ & $6 \%$ & $69 \%$ & $0 \%$ & $88 \%$ \\
\hline Endurance & $0 \%$ & $1 \%$ & $39 \%$ & $1 \%$ & $58 \%$ \\
\hline Abstraction & $0 \%$ & $0 \%$ & $21 \%$ & $0 \%$ & $26 \%$ \\
\hline Visual perception & $0 \%$ & $1 \%$ & $31 \%$ & $3 \%$ & $29 \%$ \\
\hline Arithmetic & $0 \%$ & $1 \%$ & $23 \%$ & $4 \%$ & $30 \%$ \\
\hline Psychosocial & $0 \%$ & $28 \%$ & $27 \%$ & $11 \%$ & $33 \%$ \\
\hline
\end{tabular}

*Presented are the percentages of children presenting delays among those identified as members of the specific cluster; the dominating delays for each cluster are marked in bold and used for the description of the cluster.

memory/concentration, endurance). In the patterns three to five, delays in some further areas had also high prevalence.

\section{Variables associated with patterns of delays}

Compared to children without any delays, male and younger children had a higher risk for any combination of delays (Table 4). The effects of both factors were less pronounced for disorders of language development (Pattern 1 or 2), while they were substantially stronger for combinations with delays in fine body coordination (Pattern 4) and motor development (Pattern 5). Migration background was associated with a lower risk for isolated delays of pronunciation (Pattern 1) and a higher risk for all other patterns (Pattern 2 to 5) (Table 4).

\section{Discussion}

The analysis of data from school-entry examinations in a Lower Bavarian district revealed co-occurrence of delays in closely related development areas in bivariate analysis and a clustering of delays into five distinct patterns associated with sex, age and migration status.

In studies of selected, clinical populations, authors often noted co-occurrence of developmental delays. For

Table 4 Variables associated with specific patterns of delays compared to "no delays" (multivariable multinominal logistic regression analysis)

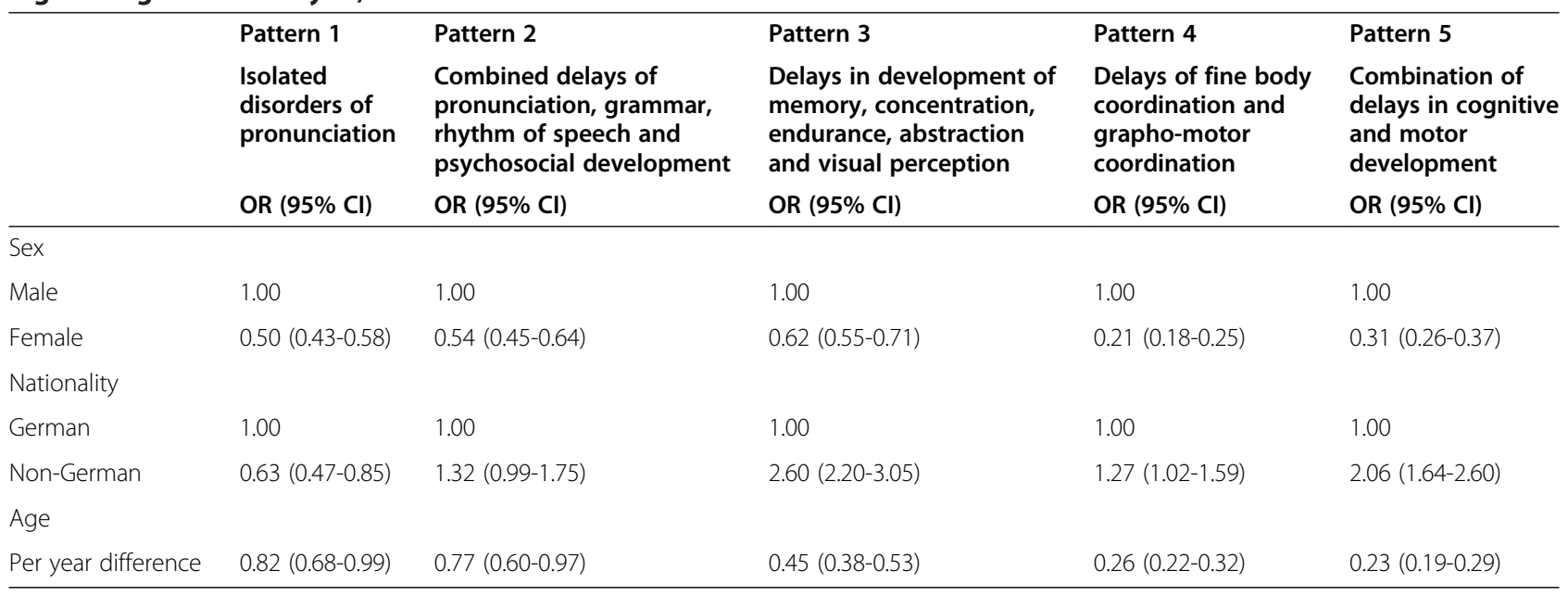

OR - odds ratio.

$\mathrm{Cl}$ - confidence interval. 
example, Kadesjö and Gillberg [25] noted that 6.1\% of children in their study population had combined delays in motor body coordination and ability of attention. In several further studies, children with specific developmental disorders were assessed for further impairments [26-30]. Generally, these studies provided evidence for clustering of developmental delays, but their results are not directly comparable with the current study in the normal, unselected population. In addition, all cited studies have in common that they assessed only a narrow selection of developmental delays.

Clustering of multiple developmental delays was not formally investigated yet. Eldred and Darrah [5] used cluster analysis to study developmental delays, but only considering gross motor coordination. In our study, a cluster analysis was carried out with respect to multiple development areas. The patterns we identified are interesting from the point of view of diagnostics on the one side and prevention on the other side. With respect to prevention of negative consequences of the delays, single delays can be addressed by single interventions, while combined delays would require a combination of interventions addressing several aspects at the same time or in sequence. For example, isolated delays in pronunciation can be directly addressed by speech therapy while combined with problems in the use of grammar might require learning the language. The question is interesting -which cannot be answered by the current crosssectional study- if the delays are independent of each other or if possibly delays in some areas negatively affect developmental chances in other areas: for example, contribute delays in cognitive development to motor development (pattern 5)? In addition, in the patterns 3 and 5 also other developmental delays beyond those used to name the clusters were rather frequent. In such case, particularly these patterns can be seen as complex delays.

Male sex and younger age were consistently identified as being associated with a higher risk of single development delays in previous analyses of the same data $[18,19]$, now they shown to be also associated with combined delays. As for younger age, this is not surprising, since the instrument is assessing the development with respect to abilities required for schooling. Some younger children might not have achieved this developmental stage yet. In such case, there might not be a true developmental delay at individual level, but the assessment is conducted too early. Migration background was less commonly associated with isolated pronunciation problems - likely not because pronunciation problems were less common in the migrants, but rather because in migrants they were more often associated with other delays.

The strengths of the analysis are the large, unselected sample from the normal population, collected from consecutive years and examined by the same medical team.
A limitation of our analysis is that only dichotomous outcomes: presence or absence of delays was studied and no information about the severity of delays was collected. A more detailed knowledge of the severity of the delays would allow a better understanding of the need of intervention. Also, we did not study the improvement of delays over time, and it is not fully clear which of those represent just a variation of individual development and which some form of a permanent pathology. In addition, the clinical implications of combined delays are not clear then their long term consequences were not studied yet. We also cannot determine, if interventions would help reducing the burden of delays, but we assume that even if the delays can spontaneously resolve over time, interventions could improve the adjustment of the children.

\section{Conclusions}

Most preschool children are going through an intact development without significant deficits in the acquisition of skills relevant for schooling. However, some children display development delays, and those with delays often have not just a single delay but rather there is some cooccurrence of delays in form of specific patterns. This co-occurrence of delays in multiple areas should be considered in designing intervention strategies as addressing several areas in a parallel fashion might be particularly effective. In the future, more attention should be paid to combined developmental delays, especially regarding combinations of delays of motor function and of cognition. Furthermore, factors associated with specific patterns should be studied more in detail, to identify unfavorable constellations. Also, there is a need to study long term outcomes of children with combined developmental delays in a longitudinal manner. We initiated such study in the region where the reported data was collected.

\section{Competing interests}

The authors declare that they have no competing interests.

\section{Authors' contributions}

HLS has made substantial contributions to conception and design, has examined the children, analysed and interpreted data and drafted the manuscript. AK has made contributions to the writing of the manuscript. RTM has made contribution to conception and design, supervised the statistical analysis and has been involved in revising the manuscript critically for important intellectual content. All authors have given final approval of the final version of the manuscript.

\section{Acknowledgements}

Special thanks to Mr. Heinrich Trapp, Landrat of the District of Dingolfing- Landau, Franz Beblo, MD, Chief of the Department of Public Health Medicine in Dingolfing- Landau and Mrs. Ursula Niederreiter, Social Medicine Assistant, for supporting this study.

\section{Author details}

${ }^{1}$ Department of Public Health Medicine, District of Erding, Erding 85435, Germany. ${ }^{2}$ Department of Public Health Medicine, School of Public Health, University of Bielefeld, Bielefeld 33501, Germany. ${ }^{3}$ Department of Epidemiology, Helmholtz Centre for Infection Research, Braunschweig, Germany. ${ }^{4}$ Hannover Medical School, Hannover, Germany. 
Received: 3 July 2013 Accepted: 15 January 2014

Published: 23 January 2014

\section{References}

1. Kerstjens JM, de Winter AF, Bocca-Tjeertes IF, ten Vergert EMJ, Reijneveld SA, Bos AF: Developmental delay in moderately perterm-born children at school entry. J Pediatr 2011, 159:92-98.

2. Robert Koch-Institute: Results of the child and youth health survey. Bundesgesundheitsbl-Gesundheitsforsch-Gesundheitsschutz 2007, 50:529-908 [German].

3. Wohlfeil A: Developmental delays in children starting school with the resultant performance deficits. Öffentl Gesundhwes 1991, 53:175-80 [German].

4. The Developmental Disabilities Services and Facilities Construction Act of 1970, PL. :91-517. http://mn.gov/mnddc/dd_act/documents/FEDREG/90-DDALEGLISLATIVEHISTORY.pdf.

5. Eldred K, Darrah J: Using cluster analysis to interpret the variability of gross motor scores of children with typical development. Phys Ther 2010, 90:1510-1518.

6. Tervo R: Identifying patterns of developmental delays can help diagnose neurodevelopmental disorders. A Pediatric Perspective 2003, 13:2-6.

7. Keogh BK, Bernheimer LP: Developmental delays in preschool children assessment over time. Eur J Spec Needs Educ 1987, 2:211-220.

8. Landgren M, Pettersson R, Kjellman B, Gillberg C: ADHD, DAMP, and other neurodevelopmental/psychiatric disorders in 6-year-old children: epidemiology and co-morbidity. Dev Med Child Neurol 1996, 38:891-906.

9. Tirosh E, Berger J, Cohen-Ophir M, Davidovitch M, Cohen A: Learning disabilities with and without attention- deficit hyperactivity disorder: parents' and teachers' perspectives. J Child Neurol 1998, 13:270-276.

10. Bishop DVM: [Handedness, clumsiness and developmental language disorders]. Neuropsychologia 1990, 28:681-690. 13.

11. Nicholoson Rl, Fawcett AJ: Comparison of deficits in cognitive motor skills among children with dyslexia. Ann Dys 1994, 44:145-164.14.

12. Cooper J, Moodley M, Reynell J: Helping Language Development. London: Edward Arnold; 1979

13. Whitehurst GJ, Fishel JE: Practitioner review: early developmental language delay: what, if anything, should the clinician do about it? J Child Psychol Psychiatry 1994, 35:613-648.

14. Frick PJ, Kamphaus RW, Lahey BB, Loeber R: Academic underachievement and the disruptive behaviour disorders. J Consult Clin Psychol 1991, 59:289-294.

15. Moffit TE: Juvenile delinquency and attention deficit disorders: boy's developmental trajectories from age 3 to age 15. Child Dev 1990, 61:893-910.

16. Valtonen $\mathrm{R}$, Ahonen $\mathrm{T}$, Lyytinen $\mathrm{P}$, Lyytinen $\mathrm{H}$ : Co-occurrence of developmental delays in a screening study of 4-year-old Finnish children. Dev Med Child Neurol 2004, 46:436-443.

17. Valtonen R, Ahonen T, Lyytinen P, Asko T: Screening for developmental risks of 4 years of age: predicting development two years later. Nordic Psychology 2007, 59(2):95-108.

18. Stich HL, Baune BT, Caniato RN, Krämer A: Associations between preschool attendance and development impairments in pre-school children in a six-year retrospective survey. BMC Public Health 2006, 6:260.

19. Stich HL, Baune BT, Caniato RN, Mikolajczyk RT, Krämer A: Individual development of preschool children- prevalences and determinants of delays in Germany. A cross- sectional study in Southern Bavaria. BMC Pediatr 2012, 12:188.

20. Bavarian Law of Education and Instruction (BayEUG): Bavarian Law of Education and Instruction (BayEUG). In School Director's ABC. Edited by Weber W. Kulmbach: Baumann; 2001.

21. Task Force "School and Youth Health Care in the Public Health Services": The school entry examination in 1998.

22. Statistical Package for Social Sciences [computer programm]. Version 19.0. Ehningen IBM Inc; 2012. http://ibm.com/software/analytics/spss/.

23. Cohen J: Statistical Power Analysis for the Behavioral Sciences. New Jersey: Hillsdale; 1988

24. Inc SPSS: TwoStep Cluster Analysis. Chicago: Technical report; 2004

25. Kadesjö B, Gillberg C: The comorbidity of ADHD in the general population of Swedish school-age children. J Child Psychol Psychiatry 2001, 42:487-492.

26. Webster RI, Majnemer A, Platt RW, Shevell MI: Motor function at school age in children with a preschool diagnosis of developmental language impairment. J Pediatr 2005, 146:80-85.
27. Viholainen $H$, Ahonen $T$, Cantell M, Lyytinen $\mathrm{P}$, Lyytinen $\mathrm{H}$ : Development of early motor skills and language in children at risk for familial dyslexie. DMCM 2002, 44:761-69.

28. Yochman A, Ornoy A, Parush S: Co-occurrence of developmental delays among preschool children with attention-deficit-hyperactivity disorder. DMCM 2006, 48:483-488

29. Gaines R, Missiuna C: Early identification: are speech/language-impaired toddlers at increased risk for developmental coordination disorders? Child Care Health Dev 2007, 33:325-332.

30. Dewey D, Kaplan BJ, Crawford SG, Wilson BN: Developmental coordination disorder: associated problems in attention, learning, and psychosocial adjustment. Hum Mov Sci 2002, 21:905-918

doi:10.1186/1471-2431-14-18

Cite this article as: Stich et al:: Clustering of developmental delays in Bavarian preschool children - a repeated cross-sectional survey over a period of 12 years. BMC Pediatrics 2014 14:18.

\section{Submit your next manuscript to BioMed Central and take full advantage of:}

- Convenient online submission

- Thorough peer review

- No space constraints or color figure charges

- Immediate publication on acceptance

- Inclusion in PubMed, CAS, Scopus and Google Scholar

- Research which is freely available for redistribution

Submit your manuscript at www.biomedcentral.com/submit
C) Biomed Central 